\title{
Effects of nanoencapsulated aloe vera, dill and nettle root extract as feed antibiotic substitutes in broiler chickens
}

\author{
Amir Meimandipour ${ }^{1}$, Ali Nouri Emamzadeh ${ }^{2}$, and Ali Soleimani ${ }^{1}$ \\ ${ }^{1}$ Department of Animal Biotechnology, National Institute of Genetic Engineering and \\ Biotechnology (NIGEB), Tehran, Iran \\ ${ }^{2}$ Department of Animal Science, Garmsar Branch, Islamic Azad University, Garmsar, Iran
}

Correspondence to: Amir Meimandipour (meimandi@nigeb.ac.ir)

Received: 4 April 2016 - Revised: 29 November 2016 - Accepted: 8 December 2016 - Published: 17 January 2017

\begin{abstract}
Aloe vera, nettle and dill are herbs that have been used in the poultry diet as feed additives to utilise their benefits in improving performance, immune response and health of broiler chickens. However, reactive and volatile properties of bioactive compounds in herbal extracts cause limitations on direct usage of them in the diet. The use of chitosan (CS) nanoparticles for the entrapment of active components has gained interest in the last few years due to its mucous adhesiveness, non-toxicity, biocompatibility and biodegradability. This study was an effort to evaluate effects of nanoencapsulated extracts of aloe vera, dill and nettle root used in diet on performance, carcass traits and serum immunoglobulin (IgM and IgY) concentrations in broiler chickens. Chitosan nanoparticles were prepared by using ionotropic gelation principle. After nanogel preparation of herbal extracts, a total of 240 Ross (308) broiler chicks were divided into eight treatments, with three replicates of 10 birds. The eight dietary treatments consisted of control (no additives), antibiotic (bacitracin $500 \mathrm{~g} \mathrm{t}^{-1}$ ), non-encapsulated and nanoencapsulated extracts of aloe vera, dill and nettle root. In each experimental period, non-encapsulated (free extracts) and nanoencapsulated extracts of aloe vera, dill and nettle roots were added in amounts of 0.02, 0.025 and $0.05 \%$ to starter, grower and finisher diets, respectively. Birds in different treatments received the same diets during the experimental periods. Results revealed that increasing both non-encapsulated and nanoencapsulated herbal extracts to $0.05 \%$ in finisher diets improved body weight gain in the time period of 28-42 days and consequently the whole time from 1 to 42 days. However, in these periods, birds fed a diet containing nanoencapsulated dill extract had a significantly $(P<0.05)$ higher body weight gain compared with the antibiotic group, while non-encapsulated dill extract treatment was intermediate. The addition of nanoencapsulated nettle extract in diet significantly $(P<0.05)$ improved feed conversion efficiency in the 28-42-day period compared with the antibiotic group. In comparison with the antibiotic group, nanoencapsulation of dill extract could profoundly improve growth performance and can therefore be used as a substitute for antibiotics in the diet of broiler chickens.
\end{abstract}

\section{Introduction}

The modern poultry sector today is a specialised one and it concentrates more on the use of high-performance birds. Antibiotic growth promoters have been helpful in improving growth performance and feed conversion efficiency in poultry (Dibner and Richards, 2005). However, constant treatment of poultry with antibiotics may result in residue of these substances in poultry products and bacterial resistance against treatments in humans (Hughes and Heritage, 2007). Due to these threats to human health, use of antibiotics in poultry is banned. Therefore, there is a major demand for producing high-quality poultry meat at a low price without relying on antibiotics and other medicines in poultry feed and water. 
Aloe vera, nettle and dill are herbs with various antibacterial, antiseptic, anti-inflammatory, nematocidal and immunomodulatory properties. Along with using these herbs for medicinal preparations, they can also be included in the poultry diet as feed additives to utilise their benefits in improving performance, immune response and health of broiler chickens (Mehala and Moorthy, 2008; Darabighanea et al., 2012; Safamehr et al., 2012; Bahadori and Irani, 2013).

However, there are limitations on direct usage of the extracts in poultry diet. These limitations are related to hydrophobic, highly active, reactive and volatile properties of bioactive compounds in the extracts. In presence of air oxygen, the compounds are also sensitive to peroxidation and oxidative damage. Therefore, these undesirable reactions decrease efficiency of the bioactive compounds and also change natural odour and taste of the extracts. Conversely, using high amounts of the extracts directly in the diet decreases palatability and feed intake due to change in feed taste (Lee et al., 2003). With the addition of a protective layer, these substances and their properties are retained.

Even though the concepts of micro-encapsulation or nanoencapsulation and controlled release are relatively old, attention to these concepts with respect to plant extracts has only been recent. Nanocapsules exhibit a membrane-wall structure and bioactive substances are entrapped in the core or adsorbed onto their exterior. Most nanocapsules prepared from water-insoluble polymers involve heat, organic solvent or high shear force that can be harmful to the effective material stability (Allemann et al., 1993). In contrast, water-soluble polymers offer mild and simple preparation methods without the use of organic solvent and high shear force. Among available water-soluble polymers, chitosan (a polyglucosamine derived from chitin), a cellulose-like polymer located in the exoskeletons of arthropods such as crabs, shrimps, lobsters and insects (Furda, 1983), is one of the most extensively studied. This is because chitosan possesses some ideal properties of polymeric carriers for nanoparticles, such as biocompatibility, biodegradability, no toxicity, and low cost (Hejazi and Amiji, 2003). Furthermore, it possesses a positive charge and exhibits absorption enhancing effects. These properties render chitosan a very attractive material as a drug or effective material delivery carrier (LeHoux and Grondin, 1993). The positive charge in chitosan molecules also decreases possession of negative charge due to bacteria growth (Razdan and Petterson, 1994; Tiyaboonchai, 2003).

Therefore, the present study was an effort to utilise nanoencapsulated extracts of aloe vera, dill and nettle root as natural growth promoters and effective substitutions for feed antibiotics in broiler chickens. Our preliminary experiment (unpublished) shows that increasing the herbal extract concentration over the experimental period improves broiler performance. This might be due to its adaptation and/or the birds' increasing requirement for herbal extract to improve their performance. Thus, in order to overcome this require- ment, herbal extract concentration was raised over the course of the experiment.

\section{Materials and methods}

Herbal extracts were purchased from the traditional medicine department of the Barij Essence Pharmaceutical Company (Kashan, Iran). Ethanol and acetic acid were provided by Merck. The medium molecular weight chitosan, derived from crab shell and sodium triphosphate pentabasic (TPP), was purchased from Sigma-Aldrich. All the other reagents used in the experiment were of analytical grade.

\subsection{Nanoencapsulation of herbal extracts}

Nanoencapsulation of the herbal extract was performed by ionic gelation according to the procedure of Stoica et al. (2013). Chitosan was dissolved at a concentration of $1 \mathrm{mg} \mathrm{mL}^{-1}$ in $1 \%(w / v)$ acetic acid and sonicated before the solution became transparent. The dropwise addition of $10 \mathrm{~mL}$ TPP solution $\left(1 \mathrm{mg} \mathrm{mL}^{-1}\right)$ to a $25 \mathrm{mLCS}$ solution $(\mathrm{pH}=5)$, under constant stirring at room temperature, produced the formation of CS-TPP nanoparticles by ionic gelation. For the preparation of CS-TPP nanoparticles loaded with herbal extracts, $20 \%(w / v)$ extracts were added to the chitosan solution before adding the TPP solution.

\subsection{Management and experimental design}

A total of 240 1-day-old broiler chicks (Ross 308) were procured from a local hatchery and transferred to a research poultry house. At 1 day of age, the chicks were individually weighed and randomly divided into 24 pens $(100 \times$ $120 \times 75 \mathrm{~cm})$ with an equal initial weight of $132 \pm 2 \mathrm{~g}$. The pens were distributed into eight treatments of three replicates with 10 chicks in each under a completely randomised design. The chicks were reared in the litter system under standard management conditions in three experimental (starter, grower and finisher) periods until the sixth week. The basal diet was formulated according to the standards prescribed in Ross 308 Broiler Nutrition Specification, June 2007. The starter, grower and finisher diets presented in Table 1 were fed ad libitum to the birds from 1-14, 15-28 and 29-42 days of age respectively.

\subsection{Experimental diets}

The eight dietary treatments consisted of a negative control diet (basal diet without additives), a positive control diet (basal diet plus $500 \mathrm{~g}$ of antibiotic per tonne), three diets containing non-encapsulated extracts of aloe vera, dill or nettle root, and three diets containing nanoencapsulated extracts of aloe vera, dill or nettle root. In each experimental period, non-encapsulated and nanoencapsulated extracts of aloe vera, dill and nettle root were added in the amount of 0.02 , 
Table 1. Ingredients and chemical composition of basal diets in different periods.

\begin{tabular}{|c|c|c|c|}
\hline Ingredients & Starter & Grower & Finisher \\
\hline Corn & 57.00 & 60.41 & 64.76 \\
\hline Soybean meal & 37.14 & 34.22 & 29.7 \\
\hline Soybean oil & 1.20 & 1.6 & 2 \\
\hline $\mathrm{CaCO}_{3}$ & 1.26 & 1.05 & 1.02 \\
\hline Dicalcium phosphate & 1.8 & 1.52 & 1.46 \\
\hline Common salt & 0.21 & 0.2 & 0.2 \\
\hline $\mathrm{NaHCO}_{3}$ & 0.16 & 0.17 & 0.17 \\
\hline DL-methionine & 0.29 & 0.2 & 0.14 \\
\hline $\mathrm{HCl}-$ lysine & 0.24 & 0.1 & 0.05 \\
\hline L-threonine & 0.10 & 0.03 & 0 \\
\hline Vitamin $\&$ mineral premix ${ }^{1}$ & 0.6 & 0.5 & 0.5 \\
\hline Sum & 100 & 100 & 100 \\
\hline \multicolumn{4}{|l|}{ Chemical composition } \\
\hline Metabolisable energy $\left(\mathrm{kcal} \mathrm{kg}^{-1}\right)$ & 2900 & 2970 & 3040 \\
\hline Crude protein $(\%)$ & 21.09 & 19.8 & 18.05 \\
\hline Methionine (\%) & 0.45 & 0.4 & 0.35 \\
\hline Methionine + cysteine $(\%)$ & 0.9 & 0.79 & 0.69 \\
\hline Lysine $(\%)$ & 1.22 & 1.04 & 0.89 \\
\hline Threonine $(\%)$ & 0.8 & 0.69 & 0.6 \\
\hline Tryptophan (\%) & 0.19 & 0.17 & 0.14 \\
\hline Arginine (\%) & 1.26 & 1.07 & 0.94 \\
\hline Calcium (\%) & 1.01 & 0.85 & 0.81 \\
\hline Available phosphorous (\%) & 0.48 & 0.42 & 0.4 \\
\hline $\mathrm{Na}(\%)$ & 0.15 & 0.15 & 0.15 \\
\hline Linoleic acid $(\%)$ & 1.2 & 1.13 & 0.95 \\
\hline
\end{tabular}

${ }^{1}$ The premix includes A: $10000 \mathrm{IU}, \mathrm{D}_{3}: 5000$, E: $50 \mathrm{IU}, \mathrm{K}: 3 \mathrm{mg}, \mathrm{B}_{1}: 2 \mathrm{mg}, \mathrm{B} 2: 6 \mathrm{mg}$, niacin: $60 \mathrm{mg}$, pantothenic acid: $15 \mathrm{mg}, \mathrm{B}_{6}: 3 \mathrm{mg}$, biotin: $0.1 \mathrm{mg}$, folic acid: $1.75 \mathrm{mg}$, $\mathrm{B}_{12}$ : 0.016; Cu: $16 \mathrm{mg}$, I: 1.26 , Fe: $40 \mathrm{mg}$, Mn: $120 \mathrm{mg}$, Se: $0.3 \mathrm{mg}$, and Zn: $100 \mathrm{mg}$.

0.025 and $0.05 \%$ to starter, grower and finisher diets (Table 1) respectively.

\subsection{Collection of data}

Data on body weight and feed consumption were recorded at weekly intervals and mortality was recorded at occurrence. From the data above, body weight gain (BWG) and feed consumption per bird and feed conversion ratio were calculated.

\subsection{Sample preparations and measurements}

The blood samples collected from jugular veins (nine chicks per treatment) at 35 and 42 days of age were allowed to clot at a room temperature of $28 \pm 10^{\circ} \mathrm{C}$ for $2 \mathrm{~h}$ and were centrifuged at $3000 \mathrm{rpm}$ for $5 \mathrm{~min}$. The sera were then separated and frozen at $-40{ }^{\circ} \mathrm{C}$ before assay. Serum levels of immunoglobulins (IgY and IgM) were determined by the ELISA (enzyme-linked immunosorbent assay) technique using a commercial kit of IgY and IgM (Bethyl Laboratory, Inc., USA) following manufacturer instructions with slight modification as described by Hamal et al. (2006). The samples were analysed in triplicate. At the end of the experimen- tal period, after blood sampling, the birds were slaughtered following the standard procedures for stunning, exsanguination and de-feathering. Thereafter, carcass, breast, thigh, liver and intestines were immediately removed and weighed. The data were expressed as the percentage of total carcass weight.

\subsection{Statistical analysis}

The data collected on various parameters were subjected to statistical analysis using the GLM (general linear model) procedure of SAS software (SAS Institute, 1990) based on completely randomised design with three replications. The Duncan's test was used to elucidate differences between treatment means, with the $0.05 \%$ level considered significant. Results are reported as the mean and pooled standard error of mean (SEM).

\section{Results and discussion}

Table 2 represents the effect of free herbal extracts and their nanoencapsulated counterparts in broiler diet on BWG. Results indicated that the addition of herbal extracts freely and nanoencapsulated in diet did not significantly $(P>0.05)$ affect BWG in the time periods of 1-14 and 14-28 days. Thereafter, however, the improved BWG in the time periods of 28-42 days and consequently 1-42 days was probably due to increase of both non-encapsulated and nanoencapsulated herbal extracts to $0.05 \%$ in finisher diets. In these periods, birds fed a diet containing nanoencapsulated dill extract had a significantly $(P<0.05)$ higher BWG compared with the antibiotic group, while non-encapsulated dill extract treatment was intermediate. This study is the first report to evaluate the nanoencapsulated form of herbal extract in broiler diet. Previous studies using aloe vera extract (Swaim et al., 1992) and dill powder (Bahadori and Irani, 2013) in broiler chicken diet demonstrated higher BWG compared to the control. However, Mehala and Moorthy (2008) showed a total lack of impact on body weight gain when using different levels of aloe vera powder in the broiler chickens' diet during the whole experimental period. It is possible that the significant variability in the above-mentioned results is the combined effect of differences in dose, duration and processing of the medicinal plants, essential oils, and/or the different husbandry conditions. However, in the present study, effective delivery of dill extract via its nanoencapsulation and the antimicrobial properties of chitosan nanoparticles used to make capsules caused the higher body weight gain of broiler chickens as compared with the antibiotic group.

As indicated in Table 3, there was no significant difference in feed intake between treatment groups in different periods $(P>0.05)$. However, in the total experimental period $(1-42$ days), the highest and lowest amount of feed intake in chicks was obtained numerically ( $P=0.111$ ) by adding nanoencapsulated and non-encapsulated extract of nettle root to the diet, respectively. Bird feed intake responses to a diet containing 
Table 2. Effect of dietary treatments on body weight gain $(\mathrm{g})$ in broiler chickens.

\begin{tabular}{lrrrr}
\hline Additive type & \multicolumn{4}{c}{ Experimental periods (days) } \\
\cline { 2 - 5 } & $1-14$ & $14-28$ & $28-42$ & $1-42$ \\
\hline Negative control (no additive) & 546 & 934 & $1060^{\mathrm{c}}$ & $2540^{\mathrm{c}}$ \\
Positive control (antibiotic) & 536 & 940 & $1136^{\mathrm{bc}}$ & $2613^{\mathrm{bc}}$ \\
Non-encapsulated extract of nettle root & 534 & 946 & $1100^{\mathrm{c}}$ & $2580^{\mathrm{bc}}$ \\
Non-encapsulated extract of dill & 562 & 938 & $1210^{\mathrm{abc}}$ & $2710^{\mathrm{abc}}$ \\
Non-encapsulated extract of aloe vera & 528 & 971 & $1177^{\mathrm{abc}}$ & $2676^{\mathrm{bc}}$ \\
Nanoencaps. extract of nettle root & 557 & 908 & $1293^{\mathrm{ab}}$ & $2758^{\mathrm{ab}}$ \\
Nanoencaps. extract of dill & 569 & 984 & $1317^{\mathrm{a}}$ & $2870^{\mathrm{a}}$ \\
Nanoencaps. extract of aloe vera & 554 & 919 & $1200^{\mathrm{abc}}$ & $2673^{\mathrm{bc}}$ \\
\hline$P$ value & 0.626 & 0.941 & 0.027 & 0.0127 \\
SEM & 16.7 & 45.5 & 50.0 & 53.8 \\
\hline a-c In each column, means with different superscripts differ significantly $(P<0.05){ }^{1}$ SEM: pooled \\
standard error of mean.
\end{tabular}

Table 3. Effect of dietary treatments on feed intake $(\mathrm{g})$ and feed conversion ratio in broiler chickens.

\begin{tabular}{|c|c|c|c|c|c|c|c|c|}
\hline \multirow[t]{3}{*}{ Additive type } & \multicolumn{8}{|c|}{ Experimental periods (days) } \\
\hline & \multicolumn{2}{|c|}{$1-42$} & \multicolumn{2}{|c|}{$14-28$} & \multicolumn{2}{|c|}{$28-42$} & \multicolumn{2}{|c|}{$1-14$} \\
\hline & $\mathrm{FI}^{\mathrm{a}}$ & FCR & FI & FCR & FI & FCR & FI & FCR \\
\hline Negative control (no additive) & 886 & 1.62 & 1647 & 1.76 & 2179 & $2.06^{\mathrm{a}}$ & 4740 & 1.87 \\
\hline Positive control (antibiotic) & 905 & 1.69 & 1552 & 1.65 & 2187 & $1.92^{\mathrm{abc}}$ & 4643 & 1.78 \\
\hline Non-encapsulated extract of nettle root & 883 & 1.65 & 1577 & 1.67 & 2153 & $1.96^{\mathrm{ab}}$ & 4613 & 1.79 \\
\hline Non-encapsulated extract of dill & 935 & 1.66 & 1673 & 1.78 & 2126 & $1.76^{\mathrm{cd}}$ & 4734 & 1.75 \\
\hline Non-encapsulated extract of aloe vera & 938 & 1.78 & 1672 & 1.72 & 2204 & $1.87^{\mathrm{bcd}}$ & 4813 & 1.80 \\
\hline Nanoencaps. extract of nettle root & 931 & 1.67 & 1623 & 1.79 & 2233 & $1.73^{\mathrm{d}}$ & 4887 & 1.77 \\
\hline Nanoencaps. extract of dill & 933 & 1.64 & 1633 & 1.66 & 2313 & $1.76^{\mathrm{cd}}$ & 4880 & 1.70 \\
\hline Nanoencaps. extract of aloe vera & 940 & 1.70 & 1629 & 1.77 & 2115 & $1.76^{\mathrm{cd}}$ & 4684 & 1.75 \\
\hline$P$ value & 0.222 & 0.76 & 0.723 & 0.575 & 0.284 & 0.003 & 0.111 & 0.128 \\
\hline SEM $^{1}$ & 19.2 & 0.059 & 68.7 & 0.092 & 54.6 & 0.058 & 71.9 & 0.034 \\
\hline
\end{tabular}

a-d In each column, means with different superscripts differ significantly $(P<0.05) .{ }^{1}$ SEM: pooled standard error of mean.

a herbal plant and its derivatives differ depending on extract dosage and the types of herbal plant. For example, no significant difference in mean feed intake was found among groups administered extract of aloe vera gel (Durrani et al., 2008), Curcuma longa (Ismail et al., 2004), Berberis lycium (Chand et al., 2005), and a mixture of cinnamon, oregano and pepper (Hernandez et al., 2004). Conversely, Durrani et al. (2007) on Mentha longifolia and Guo et al. (2004) on Chinese herb reported significant differences in feed consumption of broiler chickens fed various herbal extracts and antibiotics. In this study, numerically higher feed intake of nanoencapsulated treatments is probably due to the use of a very low concentration of herbal extracts in preparation of the formula.

With respect to Table 3, the effect of all tested extracts was not significant $(P>0.05)$ on FCR (feed conversion ratio) in broiler chickens during different experimental periods except for the 28-42-day period. In the 28-42-day period, feeding birds with all types of nanoencapsulated extracts and also non-encapsulated extracts of dill and aloe vera significantly improved FCR compared with the control group. However, in comparison with antibiotic treatment, only the administration of the nanoencapsulated form of nettle was significant $(P<0.05)$. Similar to growth, bird FCR responses to herbal extract supplementation are still controversial. However, the most important mechanisms of plant extracts for improving FCR are their digestion-stimulating properties and antimicrobial effects. As mentioned above, nanoencapsulation could develop these properties via effective delivery of the extracts and the antimicrobial properties of chitosan (Jain et al., 2008; Safamehr et al., 2013).

Table 4 shows the effect on broiler carcass traits of using non-encapsulated and nanoencapsulated extracts in the diet. 
Table 4. Effect of dietary treatments on carcass traits in broiler chickens (expressed as a percentage) ${ }^{1}$.

\begin{tabular}{lrrrrrr}
\hline Additive type & Carcass & Breast & Thigh & Liver & Intestine & G. tract \\
\hline Negative control (no additive) & 58.5 & 42.5 & 30.6 & 2.67 & 6.79 & 15.27 \\
Positive control (antibiotic) & 62.7 & 44.1 & 30.4 & 2.87 & 6.14 & 13.69 \\
Non-encapsulated extract of nettle root & 59.0 & 44.0 & 30.5 & 2.70 & 6.83 & 14.43 \\
Non-encapsulated extract of dill & 60.5 & 44.9 & 30.3 & 4.07 & 6.54 & 14.30 \\
Non-encapsulated extract of aloe vera & 62.3 & 44.0 & 30.5 & 4.10 & 6.61 & 15.57 \\
Nanoencaps. extract of nettle root & 62.9 & 44.2 & 31.3 & 4.02 & 7.19 & 14.95 \\
Nanoencaps. extract of dill & 62.5 & 46.3 & 29.7 & 3.57 & 7.35 & 15.82 \\
Nanoencaps. extract of aloe vera & 59.3 & 46.2 & 32.6 & 3.83 & 6.26 & 14.04 \\
\hline$P$ value & 0.571 & 0.342 & 0.388 & 0.177 & 0.943 & 0.805 \\
SEM $^{2}$ & 7.62 & 1.13 & 0.81 & 0.829 & 0.761 & 1.038 \\
\hline
\end{tabular}

${ }^{1}$ Means represent nine chicks per treatment. ${ }^{2}$ SEM: pooled standard error of mean.

Table 5. Effect of dietary treatments on serum immunoglobulin (IgM and $\operatorname{IgY}$ ) concentrations on the 35 th and $42 \mathrm{nd}$ days ${ }^{1}$.

\begin{tabular}{|c|c|c|c|c|}
\hline \multirow[t]{2}{*}{ Additive type } & \multicolumn{2}{|c|}{35 days } & \multicolumn{2}{|c|}{42 days } \\
\hline & $\operatorname{IgY}\left(\mu g \mathrm{~mL}^{-1}\right)$ & $\operatorname{IgM}\left(\mu g \mathrm{~mL}^{-1}\right)$ & $\operatorname{IgY}\left(\mu g \mathrm{~mL}^{-1}\right)$ & $\operatorname{IgM}\left(\mu \mathrm{g} \mathrm{mL}^{-1}\right)$ \\
\hline Negative control (no additive) & $382^{\mathrm{c}}$ & $117^{\mathrm{d}}$ & $416^{\mathrm{e}}$ & $153^{\mathrm{e}}$ \\
\hline Positive control (antibiotic) & $403^{c}$ & $134^{\mathrm{c}}$ & $435^{\text {ed }}$ & $166^{\mathrm{de}}$ \\
\hline Non-encapsulated extract of nettle root & $435^{\mathrm{b}}$ & $145^{\mathrm{bc}}$ & $465^{\mathrm{c}}$ & $175^{\mathrm{cd}}$ \\
\hline Non-encapsulated extract of dill & $425^{\mathrm{b}}$ & $155^{\mathrm{ab}}$ & $450^{\mathrm{cd}}$ & $188^{\mathrm{abc}}$ \\
\hline Non-encapsulated extract of aloe vera & $426^{\mathrm{b}}$ & $146^{\mathrm{bc}}$ & $461^{\mathrm{cd}}$ & $181^{\mathrm{cd}}$ \\
\hline Nanoencaps. extract of nettle root & $466^{\mathrm{a}}$ & $162^{\mathrm{a}}$ & $494^{\mathrm{b}}$ & $186^{\mathrm{bc}}$ \\
\hline Nanoencaps. extract of dill & $479^{\mathrm{a}}$ & $165^{\mathrm{a}}$ & $518^{\mathrm{ab}}$ & $203^{\mathrm{a}}$ \\
\hline Nanoencaps. extract of aloe vera & $483^{\mathrm{a}}$ & $163^{\mathrm{a}}$ & $527^{\mathrm{a}}$ & $199^{\mathrm{ab}}$ \\
\hline$P$ value & 0.001 & 0.0001 & 0.0001 & 0.0001 \\
\hline SEM $^{2}$ & 7.2 & 4.1 & 8.9 & 5.1 \\
\hline
\end{tabular}

The results revealed that there was no significant $(P>0.05)$ effect on different carcass traits and relative organ weight, including percentages of carcass, breast, thigh, liver, intestines and total gastrointestinal tract. Findings of the present study are in agreement with Ismail et al. (2004) and Durrani et al. (2008), who reported that abdominal fat deposition, breast, thigh, gizzard, liver, and heart percentages of broiler chickens were not affected by aloe vera extract. However, addition of all nanoencapsulated and non-encapsulated extracts to the diet numerically increased liver weight compared to both the control and antibiotic groups. A previous study by Debersac et al. (2001) showed that water-soluble extract enhanced hepatic metabolism and increased relative liver weight in rats. The highest breast percentage was also obtained numerically by administering nanoencapsulated extracts of dill and aloe vera.

Table 5 provides the results obtained from the analysis of serum immunoglobulin (IgM and IgY) concentrations on the 35 th and 42 nd days. Compared with other treatments, admin- istering nanoencapsulated form of the extracts significantly $(P<0.05)$ enhanced $\operatorname{IgY}$ and $\operatorname{IgM}$ at 35 and 42 days of age. These findings support previous research into this area of the brain and links aloe vera extract and humoral immunity (Akhtar et al., 2012). The authors reported that oral administration of aloe vera extract resulted in higher numbers of anti-SRBC antibody (total Igs, IgM and IgG) titers. They attributed this activity to the stimulation of a humoral response to aloeride (a polysaccharide from aloe vera), which induces IL-6, a potent B-cell stimulant, to produce antibodies (Tan and Vanitha, 2004).

\section{Conclusions}

In conclusion, the results of the present study demonstrated that comparable to antibiotic treatment, the tested extracts, except for non-encapsulated nettle root could improve growth performance in broiler chickens. However, nanoencapsulation of herbal extracts with chitosan probably pro- 
foundly improves immune responses and increases broiler performance via a better delivery system and stimulation along with antimicrobial effects of chitosan nanoparticles. Further studies on nanoencapsulation of bioactive components and their influence on broiler chickens and other farm animals are underway in our lab.

\section{Data availability}

The original data of the paper will be available upon request to the corresponding author.

Competing interests. The authors declare that they have no conflict of interest.

Acknowledgement. The authors gratefully acknowledge the financial support of the National Institute of Genetic Engineering and Biotechnology.

Edited by: M. Mielenz

Reviewed by: Kuldeep Dhama and one anonymous referee

\section{References}

Akhtar, M., Hai, A., Awais, M. M., Iqbal, Z., Muhammad, F., ul Haq, A., and Anwar, M. I.: Immunostimulatory and protective effects of aloe vera against coccidiosis in industrial broiler chickens, Vet. Parasitol., 186, 170-177, 2012.

Allemann, E., Gurny, R., and Doelker, E.: Drug-loaded nanoparticles-preparation methods and drug targeting issues, Eur. J. Pharm. Biopharm., 39, 173-191, 1993.

Bahadori, M. M. and Irani, M.: The Effects of Dill Powder in Diet on Some Blood Metabolites, Carcass Characteristics and Broiler Performance, Glob. Vet., 10, 500-504, 2013.

Chand, N., Durrani, F. R., Mian, M. A., and Durrani, Z.: Effect of different levels of feed added Berberis lycium on the performance of broiler chicks, Int. J. Biotechnol., 2, 971-974, 2005.

Darabighanea, B., Zareia, A., and Zare-Shahneh, A.: The effects of different levels of aloe vera gel on ileum microflora population and immune response in broilers: a comparison to antibiotic effects, J. Appl. Anim. Res., 40, 31-36, 2012.

Debersac, P., Vernevaut, M. F., Amiot, M. J., Suschetet, M., and Siess, M. H.: Effects of a water-soluble extract of rosemary and its purified component rosmarinic acid on xenobiotic metabolizing enzymes in rat liver, Food Chem. Toxicol., 29, 109-117, 2001.

Dibner, J. J. and Richards, J. D.: Antibiotic growth promoters in agriculture: History and mode of action, Poult. Sci., 84, 634-643, 2005.

Durrani, F. R., Sultan, A., Marri, M. L., Chand, N., and Durrani, Z.: Effect of Wild Mint (Mentha longifolia) Infusion on the Overall Performance of Broiler Chicks, Pak. J. Biol. Sci., 10, 1130-1133, 2007.
Durrani, F. R., Ullah, S., Chand, N., Durrani, Z., and Akhtar, S.: Using aqueous extract of aloe vera gel as anticoccidial and immunotimulant agent in broiler production, Sarhad J. Agri., 24, 665-669, 2008.

Furda, I.: Aminopolysaccharides - their potential as dietary fiber, in: unconventional sources of dietary fiber, edited by: Furda, I., ACS Symposium Series, 214, 105-122, 1983.

Guo, F. C., Kwakkel, R. P., Soede, J., Williams, B. A., and Verstegen, M. W.: Effect of a Chinese herb medicine formulation, as an alternative for antibiotics, on performance of broilers, Br. Poult. Sci., 45, 793-797, 2004.

Hamal, K. R., Burgess, S. C., Pevzner, I. Y., and Erf, G. F.: Maternal Antibody Transfer from Dams to Their Egg Yolks, Egg Whites, and Chicks in Meat Lines of Chickens, Poult. Sci., 85, 13641372, 2006.

Hejazi, R. and Amiji, M.: Chitosan-based gastro intestinal delivery systems, J. Control. Release, 89, 151-165, 2003.

Hernandez, F., Madrid, J., Garcia, V., Orengo, J., and Megias, M. D.: Influence of two plant extract on broiler performance, digestibility, and digestive organ size, Poult. Sci., 83, 169-174, 2004.

Hughes, P. and Heritage, J.: Antibiotic growth-promoters in food animals, Assessing quality and safety of animal feeds, available at: http://ftp.fao.org/docrep/fao/007/y5159e/y5159e05.pdf, 2007.

Ismail, M., Durrani, F.R., Amjad, M.,Suhail, S. M., and Chand, N.: Effect of different levels of feed added Curcuma longa on overall performance of broiler chicks, J. Agric. Biol. Sci., 1, 1-16, 2004.

Jain, M., Ganju, L., Katiyal, A., Padwad, Y., Mishra, K. P., Chanda, S., Karan, D., Yogendra, K. M., and Sawhney, R. C.: Effect of Hippophae rhamnoides leaf extract against Dengue virus infection in human blood-derived macrophages, Phytomedical., 15, 793-799, 2008.

Lee, K. W., Everts, H., Kappert, H. J., Frehner, M., Losa, R., and Beynen, A. C.: Effects of dietary essential oil components on growth performance, digestive enzymes and lipid metabolism in female broiler chickens, Br. Poult. Sci., 44, 450-457, 2003.

LeHoux, J. G. and Grondin, F.: Some effects of chitosan on liver function in the rat, Endocrinol., 132, 1078-1084, 1993.

Mehala, C. and Moorthy, M.: Production Performance of Broilers Fed with Aloe vera and Curcuma longa (Turmeric), Int. J. Poult. Sci., 7, 852-856, 2008.

Razdan, A. and Pettersson, D.: Effect of chitin and chitosan on nutrient digestibility and plasma lipid concentrations in broiler chickens, Br. J. Nut., 72, 211-288, 1994.

Safamehr, A., Mirahmadi, M., and Nobakht, A.: Effect of nettle (Urtica dioica) medicinal plant on growth performance, immune responses, and serum biochemical parameters of broiler chickens, Int. Res. J. Appl. Basic Sci., 3, 721-728, 2012.

Safamehr, A., Fallah, F., and Nobakht, A.: Growth performance and biochemical parameters of broiler chickens on diets consist of chicory (Cichorium intybus) and nettle (Urtica dioica) with or without muti-enzyme, Iranian J. Appl. Ani. Sci., 3, 131-137, 2013.

SAS Institute: SAS Stat User's Guide Release 6.08, SAS Institute Inc., Cary, NC, 1990.

Stoica, R., Şomoghi, R., and Ion, R. M.: Preparation of chitosan tripolyphosphate nanoparticles for the encapsulation of polyphe- 
nols extracted form rose hips, Dig. J. Nano. Biostruct. P, 955963, 2013.

Swaim, S. F., Riddell, K. P., and McGuire, J. A.: Effects of tropical medications on the healing of open pad wounds in dogs, J. Am. Anim. Hosp. Associate, 28, 499-502, 1992.
Tan, B. K. H. and Vanitha, J.: Immunomodulatory and antimicrobial effects of some traditional Chinese medicinal herbs: a review, Curr. Med. Chem., 11, 1423-1430, 2004.

Tiyaboonchai, W.: Chitosan Nanoparticles: A Promising System for Drug Delivery, Naresuan Uni. J., 11, 51-66, 2003. 